\begin{tabular}{|c|l|}
\hline Title & Field crystallization of anodic niobia \\
\hline Author(s) & Habazaki, H.; Ogasawara, T.; Konno, H.; Shimizu, K.; Nagata, S.; Skeldon, P.; Thompson, G.E. \\
\hline Citation & $\begin{array}{l}\text { Corrosion Science, 49(2), 580-593 } \\
\text { https://doi.org/10.1016).corsci.2006.06.005 }\end{array}$ \\
\hline Issue Date & $2007-02$ \\
\hline Doc URL & http://hdl.handle.net/2115/27962 \\
\hline Type & article (author version) \\
\hline File Information & CS49-2.pdf \\
\hline
\end{tabular}

Instructions for use 


\title{
Field Crystallization of Anodic Niobia
}

\author{
H. Habazaki, T. Ogasawara, H. Konno
}

Graduate School of Engineering, Hokkaido University, N13-W8, Sapporo 060-8628, Japan

K. Shimizu

University Chemical Laboratory, 4-1-1 Hiyoshi, Yohokaha 223-8521, Japan

\author{
S. Nagata
}

Institute for Materials Research, Tohoku University, Sendai 980-8577, Japan

P. Skeldon and G.E. Thompson

Corrosion and Protection Centre, School of Materials, The University of Manchester, P.O.Box 88, Manchester M60 1QD, U.K. 
Abstract

Influences of electrolyte, pre-thermal treatment and substrate composition have been examined to elucidate the mechanism of field crystallization of anodic niobia formed on magnetron-sputtered niobium. The field crystallization occurs during anodizing at $100 \mathrm{~V}$ in $0.1 \mathrm{~mol} \mathrm{dm}^{-3}$ ammonium pentaborate electrolyte at $333 \mathrm{~K}$, with the crystalline oxide growing more rapidly than the amorphous oxide, resulting in petal-like defects. The nucleation of crystalline oxide is accelerated by pre-thermal treatment of the niobium at $523 \mathrm{~K}$ in air, while vacuum treatment hinders nucleation. Notably field-crystallization is also absent in $0.1 \mathrm{~mol}$ $\mathrm{dm}^{-3}$ phosphoric acid electrolyte or when anodizing Nb-10at.\% $\mathrm{N}$ and Nb-29at.\% W alloys in the ammonium pentaborate electrolyte. The behaviour is explained by the role of the air-formed oxide in providing nucleation sites for field crystallization at about $25 \%$ of the thickness of the subsequently formed anodic film, the location being due to the growth mechanism of the anodic oxide and the nature of crystal nuclei. Incorporation of tungsten, nitrogen and phosphorus species to this depth suppresses the field crystallization. However, boron species occupy a relatively shallow layer and are unable to affect the nucleation sites.

Keywords: A, sputtered films, B, SEM, GDOES, RBS, C, anodic films 


\section{Introduction}

Niobium and tantalum form generally amorphous anodic oxides, with the growth proceeding simultaneously at the metal/film interface by anion ingress and at the film/electrolyte interface by cation egress with a cooperative mechanism of ionic transport [1, 2]. Such anodic films are of practical importance as dielectrics of solid electrolytic capacitors. However, when a high electric field is applied to the films in electrolyte at increased temperatures, field crystallization occurs. Crystalline oxide is nucleated in the amorphous oxide, followed by its radial growth, leading to the progressive deterioration of the dielectric properties [3-9]. Field crystallization was first described by Vermilyea for anodic films on tantalum [3]. The logarithm of incubation time for crystalline oxide formation increased linearly with decrease of the field strength, while formation voltage, electrolyte temperature and impurity at the metal surface strongly influenced the nucleation of the crystalline oxide. Jackson examined the influence of electrolyte parameters, concluding that increase in $\mathrm{pH}$ and electrolyte concentration retarded the nucleation of the crystalline oxide in anodic films on tantalum [6]. The influence of thermal oxide on the field crystallization has also been reported [10].

Field crystallization occurs more readily in anodic films on niobium compared with those on tantalum [11]. Similar to anodic tantala, cracks are developed at the nucleation sites, with the pre-formed, outer, amorphous oxide layer being rolled up, forming petal-like defects, during subsequent growth of the crystalline oxide. The crystalline oxide is nucleated preferentially at the convex surfaces of chemically polished niobium leading Nagahara et al. to suggest an association with strong tensile stress [8]. Impurity at such regions, from preferred cathodic activity, may have played a role in the crystallization. Indeed, for anodic tantalum, it has been reported that inclusions provide nucleation sites [4]. A strong influence of electrolyte has been reported, with phosphoric acid suppressing markedly the field 
crystallization [6, 11], although the reason is not yet clarified. Thus, additional studies are needed to gain further insight into the mechanism of field crystallization of niobia and tantala and dielectric degradation.

In contrast to bulk metallic materials, often containing inclusions, precipitates and second phases, it is well known that sputtering deposition results in the formation of single phase materials with impurity and alloying elements dissolving homogeneously into the primary phase[12-14]. The single phases are formed exceeding the solubility limit of the impurity and alloying elements at equilibrium. In the present study, field crystallization of anodic niobia has been investigated using magnetron sputtered niobium and niobium alloys. By using magnetron sputtered materials, the influence of chemical heterogeneity of metal substrate on field crystallization of anodic niobia can be eliminated. Thus, the influences of the type of electrolyte, pre-thermal treatment and substrate composition have been examined with particular attention paid to the beneficial influence of foreign species incorporated into the oxide.

\section{Experimental}

Niobium and niobium alloy films containing nitrogen and tungsten were prepared by magnetron sputtering on to glass, silicon and aluminium substrates. Aluminium substrates were electropolished and subsequently anodized in $0.1 \mathrm{~mol} \mathrm{dm}^{-3}$ ammonium pentaborate electrolyte to $200 \mathrm{~V}$ to provide highly flat surfaces. A 99.9\% pure niobium disk of $100 \mathrm{~mm}$ diameter was used as a target. Selected specimens were then thermally treated in air or in vacuum of $\sim 10^{-3}$ Pa for $1.8 \mathrm{ks}$ at $523 \mathrm{~K}$. For the preparation of an Nb-W alloy, small disks of 99.9\% pure tungsten, of $20 \mathrm{~mm}$ diameter, were placed symmetrically on the sputter erosion region of the niobium target. Sputtering was performed in argon at $\sim 0.2 \mathrm{~Pa}$ for the preparation of niobium and the Nb-W alloy and in a mixture of argon and nitrogen for the 
$\mathrm{Nb}-\mathrm{N}$ alloy. Niobium and alloy specimens were then anodized at 5 or $50 \mathrm{~A} \mathrm{~m}^{-2}$ to selected voltages, with and without current decay, in stirred $0.1 \mathrm{~mol} \mathrm{dm}^{-3}$ ammonium pentaborate and $0.1 \mathrm{~mol} \mathrm{dm}^{-3}$ phosphoric acid electrolytes at $333 \mathrm{~K}$. A platinum sheet was used as a counter electrode.

Surfaces and cross-sections of the anodized specimens were observed by a JEOL JSM-6500F field emission gun scanning electron microscope. For the cross-sectional observation, the anodized specimen with silicon substrate was cleaved. For probing the depth distributions of the electrolyte-derived species in anodic films, glow discharge optical emission spectroscopy (GDOES) analysis was undertaken using a Jobin-Yvon 5000 RF instrument in an argon atmosphere of $898 \mathrm{~Pa}$ by applying RF of $13.56 \mathrm{MHz}$ and power of 40 W. Light emissions were monitored with a sampling time of $0.01 \mathrm{~s}$ to obtain depth profiles, using spectral lines at 313.079, 429.461, 149.262, 249.678, 177.499 and $130.217 \mathrm{~nm}$ for niobium, tungsten, nitrogen, boron, phosphorus and oxygen respectively. The alloy and anodic film compositions were determined using Rutherford backscattering spectroscopy (RBS) with $2.0 \mathrm{MeV} \mathrm{He}^{2+}$ ions. The scattered particles were detected at $170^{\circ}$ to the incident beam direction, which was normal to the specimen surface. The data were analysed using the RUMP program.

\section{Results}

\section{Influence of electrolyte}

Figure 1 shows the current decay curves of niobium during anodizing at $100 \mathrm{~V}$ in the ammonium pentaborate and phosphoric acid electrolytes. The current decreases steeply after reaching the formation voltage of $100 \mathrm{~V}$ at about $70 \mathrm{~s}$ in both electrolytes. The decrease continues for $7.2 \mathrm{ks}$ in the phosphoric acid electrolyte with the rate diminishing with time, in the manner typical of uniform anodic films that grow by a high field mechanism. In the 
ammonium pentaborate electrolyte, a current increase occurs, associated with field crystallization of the anodic niobia. A scanning electron micrograph reveals oxide pushed back and curled around the crystalline regions (Fig 2(a)), contrasting with the flat, featureless surface formed in phosphoric acid electrolyte (Fig. 2(b)). The formation of crystalline oxide in the ammonium pentaborate electrolyte was confirmed by transmission electron microscopy.

As shown in the GDOES depth profiles, boron and phosphorus species are incorporated into the outer 10 and $50 \%$ respectively of the anodic films formed in the respective electrolytes (Fig. 3(a,b)). The increased intensity of the boron signal at the substrate and the relatively high background in the oxide arise due to overlapping of light emitted from niobium $(249.697 \mathrm{~nm})$ with the measured boron line $(249.678 \mathrm{~nm})$. The wavy profile of niobium in the oxide arises from interference of light reflected at the oxide film surface and at the metal/film interface. Further, it is evident that hydrogen species slightly enrich in the metal substrate immediately beneath the anodic film, which will be discussed in a separate paper.

The concentration of phosphorus species in the anodic film has been determined by RBS analysis. The simulated spectrum, obtained using the composition and thickness for the film layers of Table 1, fits well with the experimental spectrum (Fig. 4). About 7 at.\% phosphorus, expressed as $\{[\mathrm{P}] /([\mathrm{Nb}]+[\mathrm{P}])\}$, is incorporated into the outer $47 \%$ of the film. The agreement with the distribution from GDOES indicates similar sputtering rates for the phosphorus-containing and phosphorus-free film regions during GDOES analysis.

\section{$\underline{\text { Influence of thermal oxide }}$}

Thermal treatment of the niobium in air at $523 \mathrm{~K}$ for $1.8 \mathrm{ks}$ prior to anodizing at 100 $\mathrm{V}$ in $0.1 \mathrm{~mol} \mathrm{dm}^{-3}$ ammonium pentaborate electrolyte at $333 \mathrm{~K}$ results in current increase at reduced anodizing time compared with the as-deposited niobium, (Fig. 5). Scanning electron 
micrograph of the thermally treated specimen after anodizing for 1.5 ks (Fig. 6) depicts a number of small nucleated crystals in addition to the radially grown crystals. The number of crystalline regions is larger than that without thermal treatment, suggesting accelerated nucleation of crystalline niobium oxide by thermal treatment in air. In contrast, thermal treatment in vacuum suppresses the crystalline oxide formation, with no current increase revealed in Fig. 5. The field crystallization is usually observed during anodizing at a constant voltage, but the thermal treatment in air enables field crystallization even during anodizing at a constant current density of $5 \mathrm{~A} \mathrm{~m}^{-2}$ (Fig. 7). The formation voltage rises approximately linearly to $200 \mathrm{~V}$ with growth of uniform amorphous oxide on the sputter-deposited niobium; however, with prior thermal treatment, the voltage rises at a reduced rate from $120 \mathrm{~V}$, becoming approximately constant at $140 \mathrm{~V}$. Fig. 8 reveals the surface of the specimen, with prior thermal treatment, after anodizing to $140 \mathrm{~V}$. At this voltage, numerous crystals in various stages of development are disclosed, with some crystalline regions appearing crack-free. In contrast, no crystalline oxide was developed in the anodic film formed to $100 \mathrm{~V}$, without current decay, at the same current density on the thermally treated niobium.

Since the $140 \mathrm{~V}$ film contains a number of small, early stages of crystalline oxide, cross-sectional observations should provide some information of depth position of nucleated crystalline oxide. Cross-sections of thermally treated niobium, anodized to $140 \mathrm{~V}$, reveal regions of uniform amorphous anodic film, $375 \pm 3 \mathrm{~nm}$ thick (Fig 9), attached to the columnar grained substrate. At other regions, the early stages of development of crystalline oxide, located between an outer layer of amorphous oxide and the metal substrate, is evident. Of particular significance, the thickness of the amorphous oxide is reduced by a factor of about 0.3 compared with that of the crystal-free amorphous film region. Further, the residual niobium is thinnest beneath the crystalline oxide, as a consequence of a locally enhanced oxidation rate. 


\section{Influence of alloying}

Alloying of niobium with 10 at.\% nitrogen or 29 at.\% tungsten suppresses field crystallization, as evident from the continuous decrease in current at $100 \mathrm{~V}$ in $0.1 \mathrm{~mol} \mathrm{dm}^{-3}$ ammonium pentaborate electrolyte at $333 \mathrm{~K}$ (Fig. 10) and absence of crystalline oxide at the anodized surface when observed by scanning electron microscopy.

GDOES depth profiles of the alloys anodized to $100 \mathrm{~V}$ revealed nitrogen and tungsten species in the inner 70\% of the films (Fig 11). The sputtering time for the film on the $\mathrm{Nb}-29$ at\% $\mathrm{W}$ alloy is approximately half that of the film on the $\mathrm{Nb}-10$ at\% $\mathrm{N}$ alloy, implying an increased sputtering rate for the tungsten-containing inner layer compared with the tungsten-free outer layer. This is also supported by the consequently increased signal for niobium in the inner layer.

\section{Discussion}

The study demonstrates that field crystallization of anodic niobia occurs in ammonium pentaborate electrolyte on sputter-deposited niobium, free from chemical heterogeneities, which are considered to be initiation sites in bulk material [4]. The sputter-deposited niobium is less susceptible to field crystallization than chemically polished bulk niobium anodized in phosphoric acid electrolyte, which undergoes extensive crystallization [8]. The air-formed oxide evidently has a key role in the process. Thus, thermal treatment of the niobium in air accelerates growth of crystalline oxide, while treatment in vacuum reduces the susceptibility. Thermal treatment of anodized niobium at $523 \mathrm{~K}$ can thin anodic oxides by a few nanometres according to optical measurements [15], possibly due to diffusion of oxygen from the film to the metal. Further, XPS indicates that air-formed oxides, composed mainly of $\mathrm{Nb}_{2} \mathrm{O}_{5}$, are reduced to $\mathrm{Nb}_{2} \mathrm{O}$ during vacuum annealing at $523 \mathrm{~K}$ without 
significant change of the oxide thickness $[16,17]$; $\mathrm{Nb}_{2} \mathrm{O}_{5}$ is regenerated by re-oxidation in air at room temperature. Although the air-formed oxides before and after the annealing/re-oxidation treatments are amorphous, short- and medium-range ionic re-arrangements may modify the tendency to nucleate crystalline oxide. To confirm this, future glazing incidence X-ray scattering analysis using synchrotron radiation is awaited to know the detailed local structure of the thin air-formed and thermal oxides on niobium.

Crystallization induced by thermal oxide has been found during anodizing of aluminium at a depth of about $40 \%$ of the film thickness [18], related to the transport number of $\mathrm{Al}^{3+}$ ions of $\sim 0.4$. However, unlike field crystallization of niobia, the single crystals of alumina grow in the lateral direction, forming plates. Of further relevance, effective suppression of crystalline oxide by incorporated foreign species occurs in anodic titania, which can undergo an amorphous-to-crystalline transition at formation voltages as low as $\sim 5$ $\mathrm{V}$ [19]. The crystalline oxide is developed in the region of film material formed at the metal/film interface by inward migration of $\mathrm{O}^{2-}$ ions. However, incorporation of various foreign species from an alloy substrate enables the efficient growth of uniform amorphous films to high formation voltages [20-24]. In the case of anodic titania, incorporation of electrolyte species has negligible influence on the formation of crystalline oxide, since such species do not reach the metal/film interface[25].

The present evidence indicates that the air-formed oxide on niobium provides nucleation sites for field crystallization at about $30 \%$ of the depth of the anodic film. This depth can be related to the transport number of $\mathrm{Nb}^{5+}$ ions in anodic amorphous niobia, about 0.25 [2], although precise values depend on current density and electrolyte temperature [26], as found also for anodic tantala [27]. Thus, the outer $25 \%$ of the film thickness is developed at the film surface due to migration of $\mathrm{Nb}^{5+}$ ions, with the remainder forming at the metal/film interface by migration of $\mathrm{O}^{2-}$ ions (Fig. 12(a)). The air-formed oxide introduces crystal 
pre-cursors, which are immobile during subsequent film thickening by anodizing and hence they are located at the boundary between the two film regions, i.e. at $25 \%$ of the film thickness. By analogy with titanium, field crystallization may be suppressed by incorporation of foreign species into the amorphous niobia in the vicinity of the crystal pre-cursors. Thus, no crystalline oxide is developed in the presence of incorporated phosphorus, nitrogen and tungsten species, which extend to the critical region. In contrast, boron species are ineffective due to their relatively shallow depth. Although films formed on the $\mathrm{Nb}-\mathrm{N}$ alloys contain numerous gas bubbles, with $\mathrm{N}_{2} \mathrm{O}$ gas as a component [28], a portion of nitrogen species are probably incorporated into the niobia to suppress nucleation.

In the absence of suppressing species, the crystals can grow rapidly towards the metal during the field crystallization process. To the authors' knowledge, there are no data on transport numbers in crystalline anodic niobia, but it is likely that inwardly migrating oxygen species predominate, since thermally grown crystalline niobia [29] and other crystalline anodic oxides, such as $\mathrm{ZrO}_{2}$ and $\mathrm{HfO}_{2}$, [2] are formed mainly due to inward migration of oxygen species. Thus, the crystalline oxide nuclei in films formed in ammonium pentaborate electrolyte should grow towards the metal, by the reaction of the oxygen species inwardly migrating in the crystalline oxide, and niobium outwardly migrating in the underlying amorphous oxide (Fig. 12(b)). Little further amorphous oxide grows above the initial crystalline oxide due to shortage of supply of niobium species, in accordance with the low thickness of the amorphous top layer, which is approximately $30 \%$ of that of the anodic film at regions free of crystalline oxide. The development of crystalline oxide from the metal/film interface, as shown in Fig. 9, indicates that crystalline oxide is formed at the metal/film interface at some stage, although amorphous oxide is formed initially at such locations.

The detailed growth mechanism of crystalline oxide is still uncertain, but rapid growth of crystalline oxide, under a relatively low electric field, and increase of local 
temperature may have some influence. The difference in morphology of crystals in anodic alumina and niobia may originate in the field strengths in the respective crystalline oxides; thus, the field strength is higher in crystalline alumina than in amorphous alumina, restricting growth towards the metal, contrary to the relative low field in crystalline niobia.

\section{Conclusions}

1. Field crystallization of anodic niobia formed on sputter-deposited niobium occurs at 100 $\mathrm{V}$ in $0.1 \mathrm{~mol} \mathrm{dm}^{-3}$ ammonium pentaborate electrolyte at $333 \mathrm{~K}$. Further, thermal oxide pre-formed in air accelerates the development of crystalline oxide. The crystalline oxide is nucleated at the depth of $\sim 25 \%$ from the film/electrolyte interface, and grows rapidly in the direction of the metal/film interface owing to predominant oxygen transport in the crystalline oxide and a lower field strength of the crystalline niobia compared with the amorphous oxide.

2. Incorporation into the amorphous niobia of either nitrogen and tungsten species, from alloy substrates, or phosphorus species, from a phosphoric acid electrolyte, hinders the nucleation of crystalline oxide. Importantly, the distributions of such species in the films extend to the location of potential sites of crystal growth. In contrast, boron species in films formed in ammonium pentaborate electrolyte do not reach the critical region.

Acknowledgments

The present work was supported in part by the Grant-in-Aid for Scientific Research, No. 16360353 from Japan Society for the Promotion of Science.

\section{References}

[1] L. Young, D.J. Smith, J. Electrochem.Soc., 126 (1979) 765. 
[2] J.P.S. Pringle, Electroche. Acta, 25 (1980) 1420.

[3] D.A. Vermilyea, J. Electrochem. Soc., 102 (1955) 207.

[4] D.A. Vermilyea, J. Electrochem. Soc., 104 (1957) 542.

[5] D.M. Lakhiani, L.L. Shreir, Nature, 188 (1960) 49.

[6] N.F. Jackson, J. Appl. Electrochem., 3 (1973) 91.

[7] H. Asoh, H. Odate, S. Ono, J. Surf. Finish. Soc. Jpn., 55 (2004) 952.

[8] K. Nagahara, M. Sakairi, H. Takahashi, K. Matsumoto, K. Takayama, Y. Oda, Electrochemistry, 72 (2004) 624.

[9] K. Nagahara, M. Sakairi, H. Takahashi, S. Nagata, K. Matsumoto, K. Takayama, Y. Oda, J. Surf. Finish. Soc. Jpn., 55 (2004) 943.

[10] Y. Pozdeev-Freeman, A. Gladkikh, J. Electronic Mat., 30 (2001) 931.

[11] N.F. Jackson, J.C. Hendy, Electrocomponent Sci. Tech., 1 (1974) 27.

[12] K. Hashimoto, P.Y. Park, J.H. Kim, H. Yoshioka, H. Mitsui, E. Akiyama, H. Habazaki, A. Kawashima, K. Asami, Z. Grzesik, S. Mrowec, Mater. Sci. Eng. A, 198 (1995) 1.

[13] K. Hashimoto, H. Habazaki, E. Akiyama, H. Yoshioka, J.H. Kim, P.Y. Park, A. Kawashima, K. Asami, Sci. Rep. Res. Inst. Tohoku Univ., 42 (1996) 99.

[14] S. Fujimoto, H. Hayashida, T. Shibata, Mater. Sci. Eng. A, 267 (1999) 314.

[15] H. Habazaki, T. Ogasawara, H. Konno, K. Shimizu, K. Asami, S. Nagata, K. Takayama, Y. Oda, P. Skeldon, G.E. Thompson, in Corrosion and Electrochemistry of Advanced Materials, in Honor of Koji Hashimoto, The Electrochemical Society, Pennington, NJ, in press.

[16] Q. Ma, R.A. Rosenberg, Appl. Surf. Sci., 206 (2003) 209.

[17] Q. Ma, P. Ryan, J.W. Freeland, R.A. Rosenberg, J. Appl. Phys., 96 (2004) 7675.

[18] K. Shimizu, K. Kobayashi, P. Skeldon, G.E. Thompson, G.C. Wood, Phil. Mag. A, 72 (1995) 1409. 
[19] A. Aladjem, J. Mater. Sci., 8 (1973) 688.

[20] H. Habazaki, K. Shimizu, S. Nagata, P. Skeldon, G.E. Thompson, G.C. Wood, Corros. Sci., 44 (2002) 1047.

[21] H. Habazaki, K. Shimizu, S. Nagata, P. Skeldon, G.E. Thompson, G.C. Wood, J. Electrochem. Soc., 149 (2002) B70.

[22] H. Habazaki, M. Uozumi, H. Konno, K. Shimizu, S. Nagata, K. Asami, P. Skeldon, G.E. Thompson, Electrochim. Acta, 47 (2002) 3837.

[23] H. Habazaki, M. Uozumi, H. Konno, S. Nagata, K. Shimizu, Surf. Coat. Tech., 169 (2003) 151.

[24] H. Habazaki, M. Uozumi, H. Konno, K. Shimizu, S. Nagata, K. Asami, K. Matsumoto, K. Takayama, Y. Oda, P. Skeldon, G.E. Thompson, Electrochim. Acta, 48 (2003) 3257.

[25] H. Habazaki, M. Uozumi, H. Konno, K. Shimizu, P. Skeldon, G.E. Thompson, Corros. Sci., 45 (2003) 2063.

[26] S. Ono, M. Baba, M. Shimoyama, H. Asoh, in Surface Oxide Films, The Electrochemical Society, Pennington, NJ, p.133 (2004).

[27] Q. Lu, P. Skeldon, G.E. Thompson, D. Masheder, H. Habazaki, K. Shimizu, Corros. Sci., 46 (2004) 2817.

[28] H. Habazaki, T. Matsuo, H. Konno, K. Shimizu, S. Nagata, K. Takayama, Y. Oda, P. Skeldon, G.E. Thompson, Thin Solid Films, 429 (2003) 159.

[29] P. Kofstad, High Temperature Corrosion. 1988, London and New York: Elsevier. p.425. 
Table 1 Results of RBS analysis of niobium anodized to $100 \mathrm{~V}$ at $50 \mathrm{~A} \mathrm{~m}^{-2}$ in $0.1 \mathrm{~mol} \mathrm{dm}^{-3}$ phosphoric acid electrolyte at $333 \mathrm{~K}$.

\begin{tabular}{lllcc}
\hline Layer & $\begin{array}{l}\text { Thickness } \\
(\mathrm{nm})\end{array}$ & Composition & {$[\mathrm{P}] /([\mathrm{Nb}]+[\mathrm{P}])$} & $\begin{array}{c}\text { Density } \\
\left(\mathrm{Mg} \mathrm{m}^{-3}\right)\end{array}$ \\
\hline Outer & 110 & $\mathrm{Nb}_{2}\left(\mathrm{PO}_{4}\right)_{0.15} \mathrm{O}_{4.78}$ & 0.07 & 4.42 \\
Inner & 125 & $\mathrm{Nb}_{2} \mathrm{O}_{5}$ & 0.00 & 4.42 \\
\hline
\end{tabular}


Figure captions

Fig. 1 Current decay curves of the sputter-deposited niobium during anodizing at $100 \mathrm{~V}$ in $0.1 \mathrm{~mol} \mathrm{dm}^{-3}$ ammonium pentaborate and $0.1 \mathrm{~mol} \mathrm{dm}^{-3}$ phosphoric acid electrolytes at $333 \mathrm{~K}$.

Fig. 2 Scanning electron micrographs of surfaces of the sputter-deposited niobium anodized at $100 \mathrm{~V}$ in (a) $0.1 \mathrm{~mol} \mathrm{dm}^{-3}$ ammonium pentaborate and (b) $0.1 \mathrm{~mol} \mathrm{dm}^{-3}$ phosphoric acid electrolyte at $333 \mathrm{~K}$ for $7.2 \mathrm{ks}$.

Fig. 3 GDOES depth profiles of the anodic films formed on the sputter-deposited niobium to $100 \mathrm{~V}$ without current decay at $50 \mathrm{~A} \mathrm{~m}^{-2}$ in (a) $0.1 \mathrm{~mol} \mathrm{dm}^{-3}$ ammonium pentaborate and (b) $0.1 \mathrm{~mol} \mathrm{dm}^{-3}$ phosphoric acid electrolyte at $333 \mathrm{~K}$.

Fig. 4 Experimental and simulated RBS spectra of the sputter-deposited niobium anodized to $100 \mathrm{~V}$ without current decay at $50 \mathrm{~A} \mathrm{~m}^{-2}$ in $0.1 \mathrm{~mol} \mathrm{dm}^{-3}$ phosphoric acid electrolyte at $333 \mathrm{~K}$.

Fig. 5 Current decay curves of the niobium specimens as-deposited, thermally treated at 523 $\mathrm{K}$ in air and vacuum for $1.8 \mathrm{ks}$ during anodizing at $100 \mathrm{~V}$ in $0.1 \mathrm{~mol} \mathrm{dm} \mathrm{ammonium}^{-3}$ pentaborate electrolyte at $333 \mathrm{~K}$.

Fig. 6 Scanning electron micrograph of the niobium specimen thermally treated at $523 \mathrm{~K}$ in air for $1.8 \mathrm{ks}$ and subsequently anodized at $100 \mathrm{~V}$ in $0.1 \mathrm{~mol} \mathrm{dm}^{-3}$ ammonium pentaborate electrolyte at $333 \mathrm{~K}$ for $1.5 \mathrm{ks}$.

Fig. 7 Voltage-time curves of the niobium specimens as-deposited and thermally treated at $523 \mathrm{~K}$ in air for $1.8 \mathrm{ks}$ during anodizing at $5 \mathrm{~A} \mathrm{~m}^{-2}$ in $0.1 \mathrm{~mol} \mathrm{dm}^{-3}$ ammonium pentaborate electrolyte at $333 \mathrm{~K}$.

Fig. 8 Scanning electron micrograph of the surface of the niobium specimen thermally treated at $523 \mathrm{~K}$ in air for $1.8 \mathrm{ks}$ and subsequently anodized to $140 \mathrm{~V}$ at $5 \mathrm{~A} \mathrm{~m}^{-2}$ in 0.1 mol dm${ }^{-3}$ ammonium pentaborate electrolyte at $333 \mathrm{~K}$. 
Fig. 9 Scanning electron micrographs of several parts of a cross-section of the niobium specimen thermally treated at $523 \mathrm{~K}$ in air for $1.8 \mathrm{ks}$ and subsequently anodized to 140 $\mathrm{V}$ at $5 \mathrm{~A} \mathrm{~m}^{-2}$ in $0.1 \mathrm{~mol} \mathrm{dm}^{-3}$ ammonium pentaborate electrolyte at $333 \mathrm{~K}$.

Fig. 10 Current decay curves of the sputter-deposited niobium, Nb-10 at\% N and Nb-29 at\% W during anodizing at $100 \mathrm{~V}$ in $0.1 \mathrm{~mol} \mathrm{dm}^{-3}$ ammonium pentaborate electrolyte at 333 K.

Fig. 11 GDOES depth profiles of the anodic films formed on the sputter-deposited (a) $\mathrm{Nb}-10$ at $\% \mathrm{~N}$ and (b) Nb-29 at\% W alloys to $100 \mathrm{~V}$ without current decay at $50 \mathrm{~A} \mathrm{~m}^{-2}$ in $0.1 \mathrm{~mol} \mathrm{dm}^{-3}$ ammonium pentaborate electrolyte at $333 \mathrm{~K}$.

Fig. 12 Schematic illustrations showing (a) nucleation and (b) growth of crystalline anodic niobia during anodizing of niobium. 


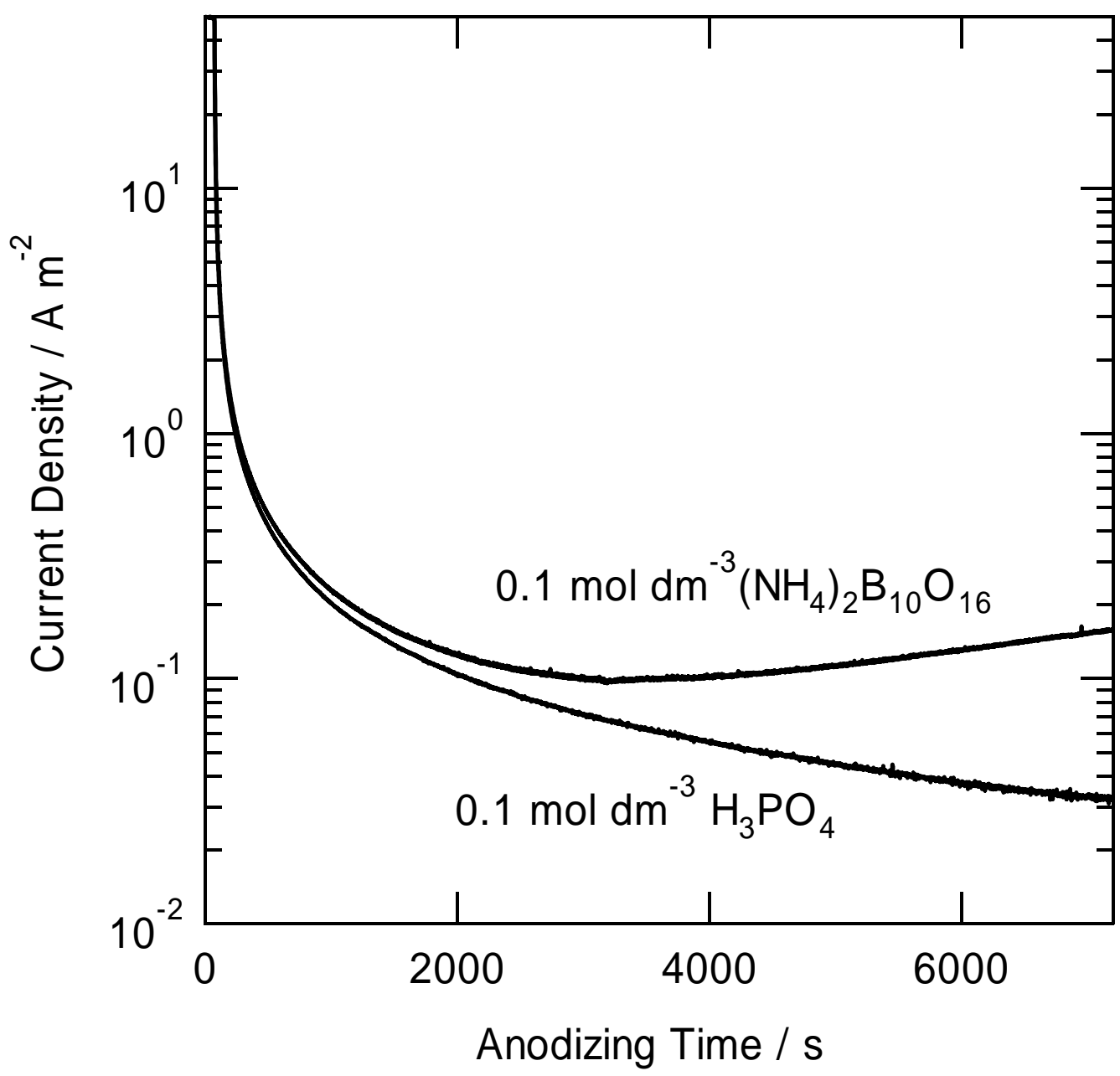

Fig. 1 Current decay curves of the sputter-deposited niobium during anodizing at $100 \mathrm{~V}$ in $0.1 \mathrm{~mol} \mathrm{dm}^{-3}$ ammonium pentaborate and $0.1 \mathrm{~mol} \mathrm{dm}^{-3}$ phosphoric acid electrolytes at $333 \mathrm{~K}$. 

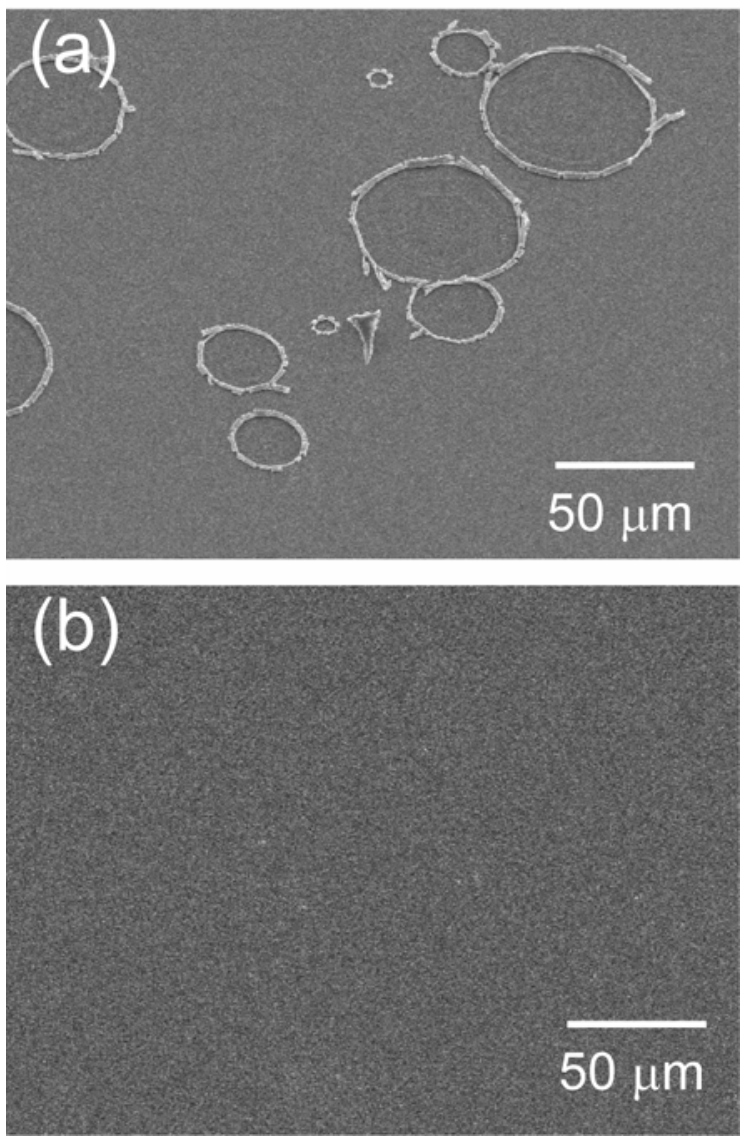

Fig. 2 Scanning electron micrographs of surfaces of the sputter-deposited niobium anodized at $100 \mathrm{~V}$ in (a) $0.1 \mathrm{~mol} \mathrm{dm}^{-3}$ ammonium pentaborate and (b) $0.1 \mathrm{~mol} \mathrm{dm}^{-3}$ phosphoric acid electrolyte at $333 \mathrm{~K}$ for $7.2 \mathrm{ks}$. 

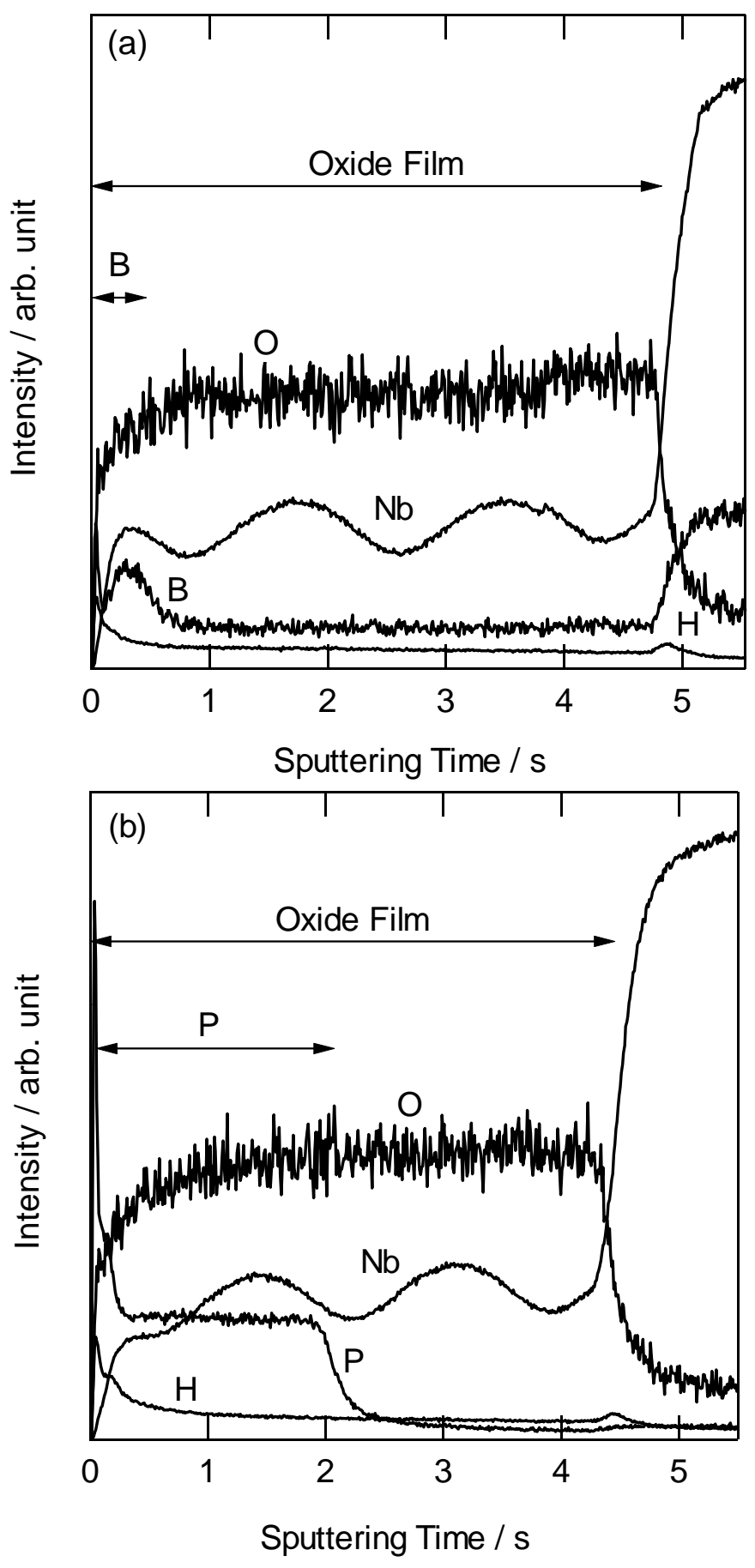

Fig. 3 GDOES depth profiles of the anodic films formed on the sputter-deposited niobium to $100 \mathrm{~V}$ without current decay at $50 \mathrm{~A} \mathrm{~m}^{-2}$ in (a) $0.1 \mathrm{~mol} \mathrm{dm}^{-3}$ ammonium pentaborate and (b) $0.1 \mathrm{~mol} \mathrm{dm}^{-3}$ phosphoric acid electrolyte at $333 \mathrm{~K}$. 


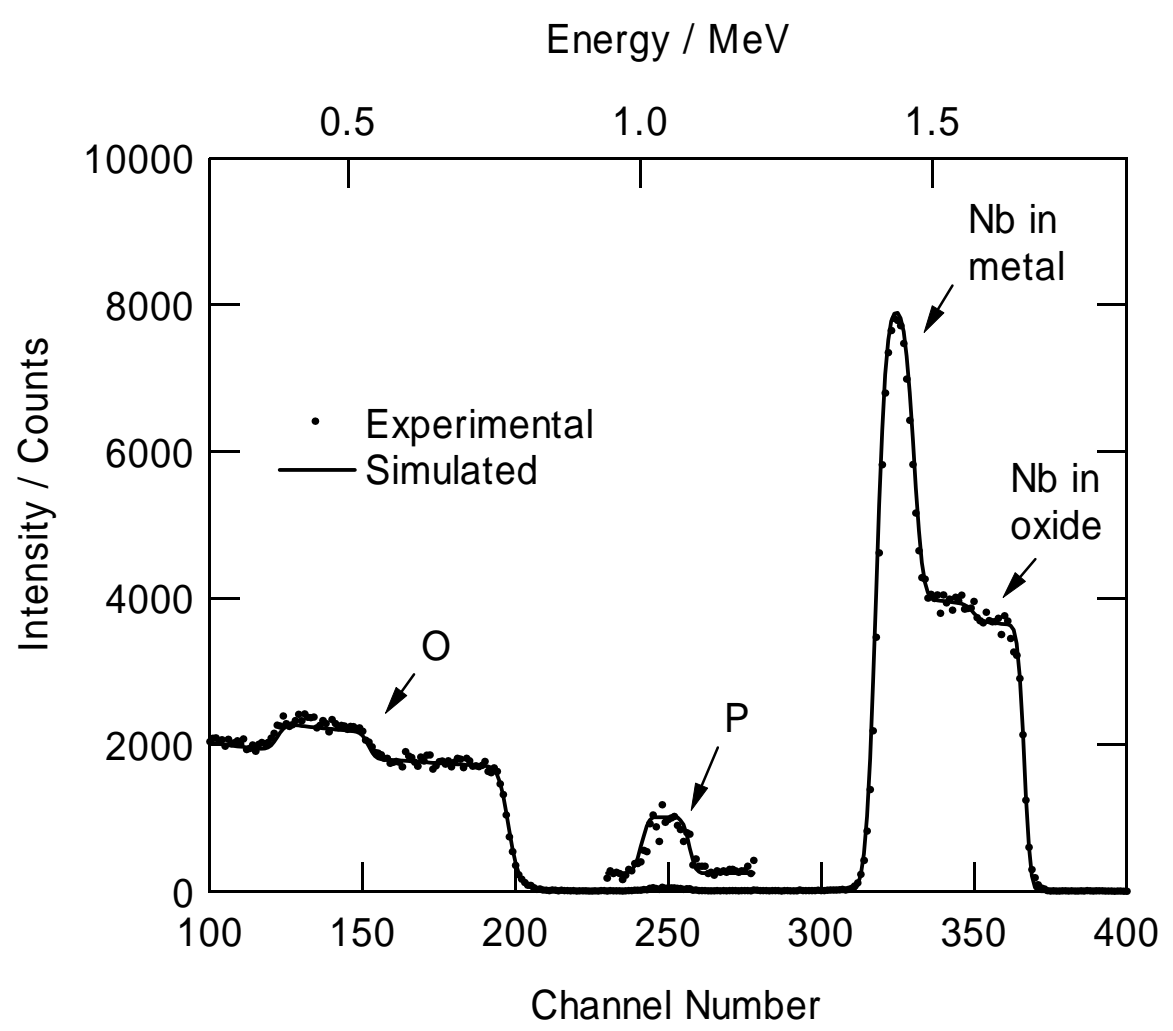

Fig. 4 Experimental and simulated RBS spectra of the sputter-deposited niobium anodized to $100 \mathrm{~V}$ without current decay at $50 \mathrm{~A} \mathrm{~m}^{-2}$ in $0.1 \mathrm{~mol} \mathrm{dm}^{-3}$ phosphoric acid electrolyte at 333 K. 


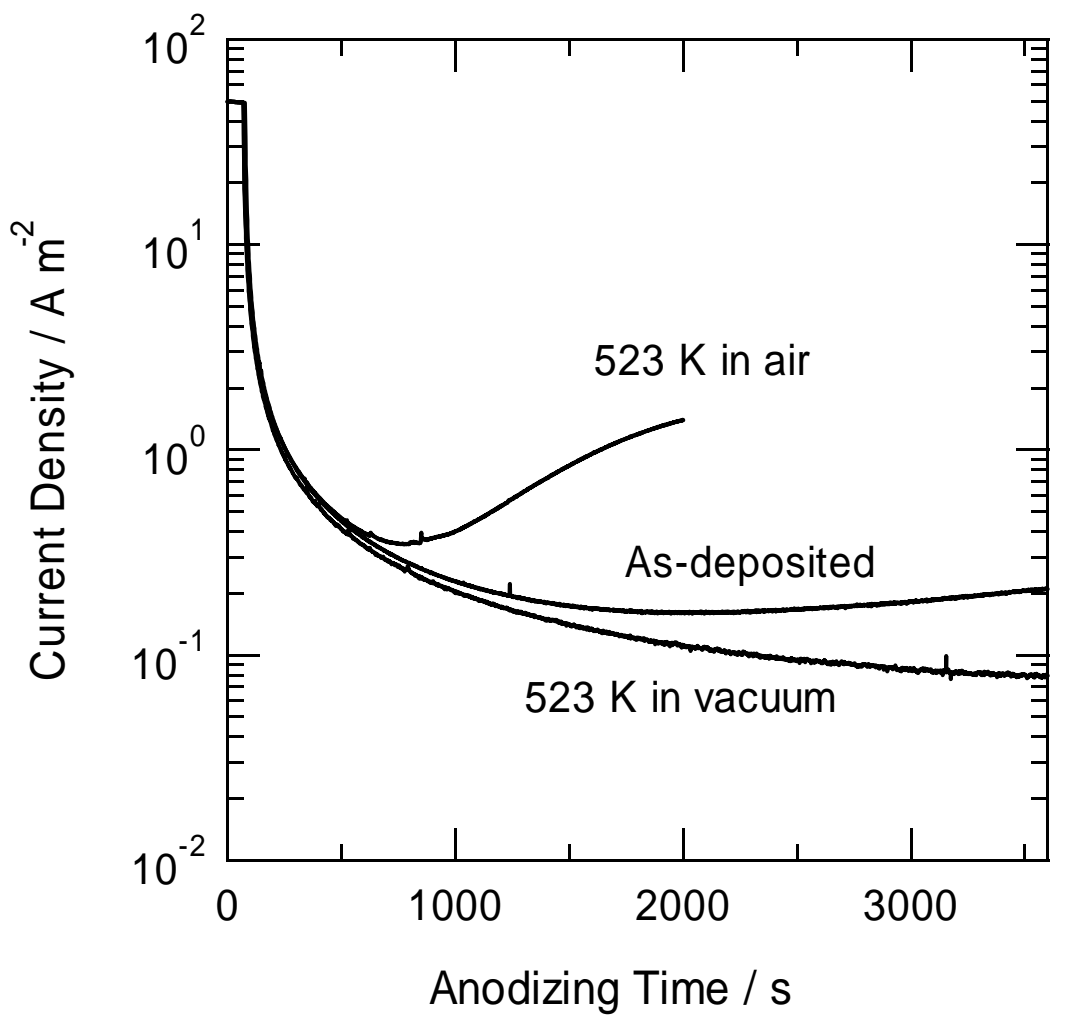

Fig. 5 Current decay curves of the niobium specimens as-deposited, thermally treated at 523 $\mathrm{K}$ in air and vacuum for $1.8 \mathrm{ks}$ during anodizing at $100 \mathrm{~V}$ in $0.1 \mathrm{~mol} \mathrm{dm}^{-3}$ ammonium pentaborate electrolyte at $333 \mathrm{~K}$. 


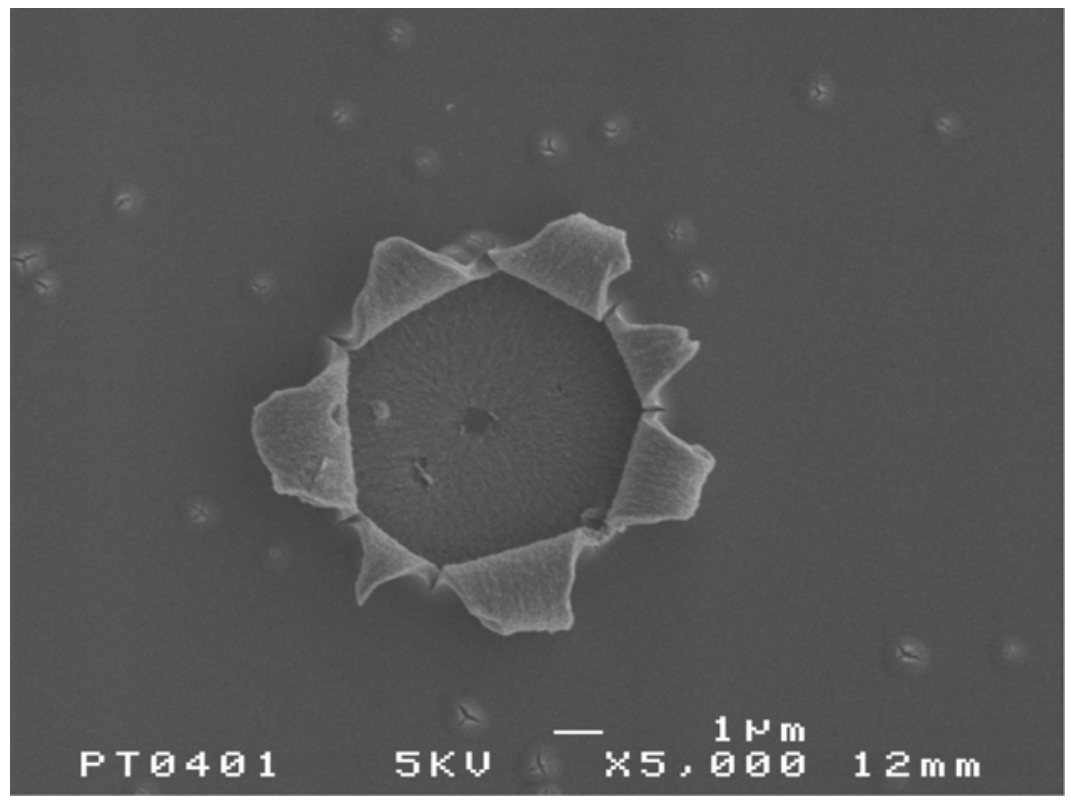

Fig. 6 Scanning electron micrograph of the niobium specimen thermally treated at $523 \mathrm{~K}$ in air for $1.8 \mathrm{ks}$ and subsequently anodized at $100 \mathrm{~V}$ in $0.1 \mathrm{~mol} \mathrm{dm}^{-3}$ ammonium pentaborate electrolyte at $333 \mathrm{~K}$ for $1.5 \mathrm{ks}$. 


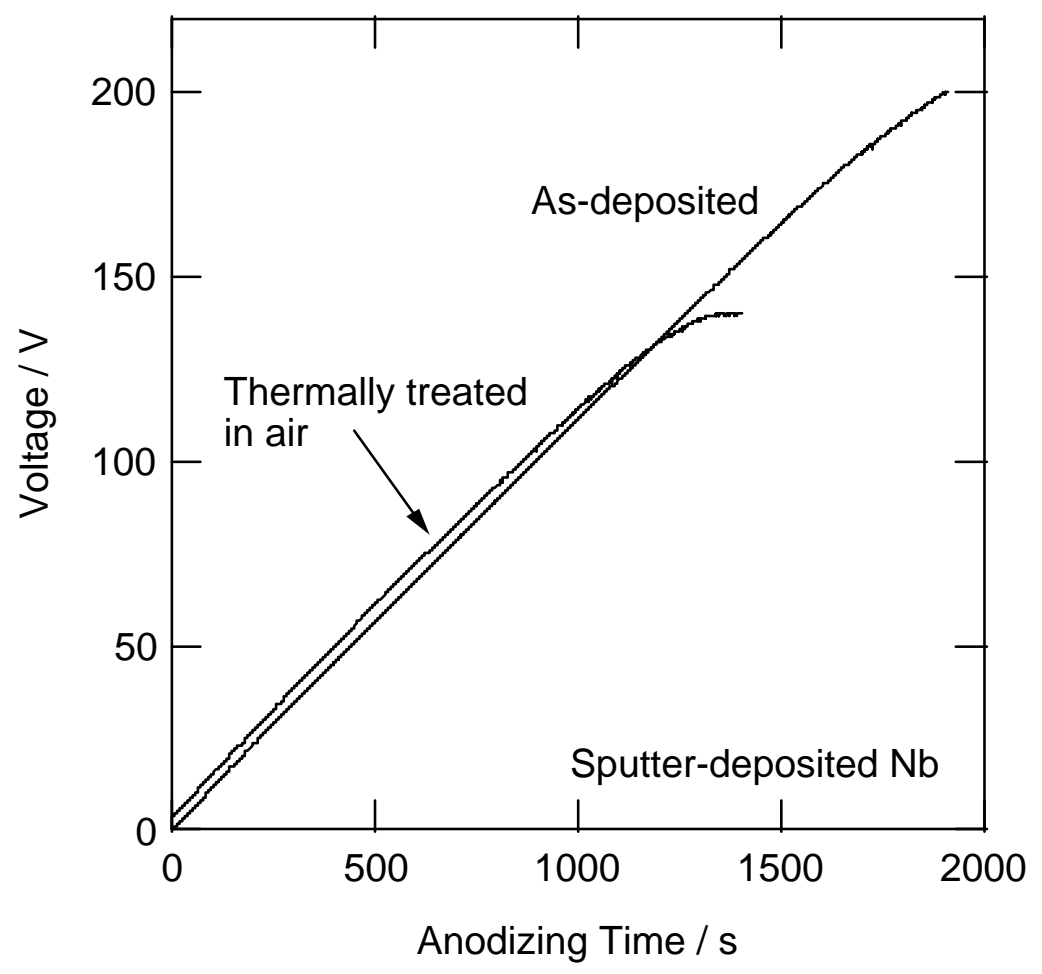

Fig. 7 Voltage-time curves of the niobium specimens as-deposited and thermally treated at $523 \mathrm{~K}$ in air for $1.8 \mathrm{ks}$ during anodizing at $5 \mathrm{~A} \mathrm{~m}^{-2}$ in $0.1 \mathrm{~mol} \mathrm{dm}^{-3}$ ammonium pentaborate electrolyte at $333 \mathrm{~K}$. 


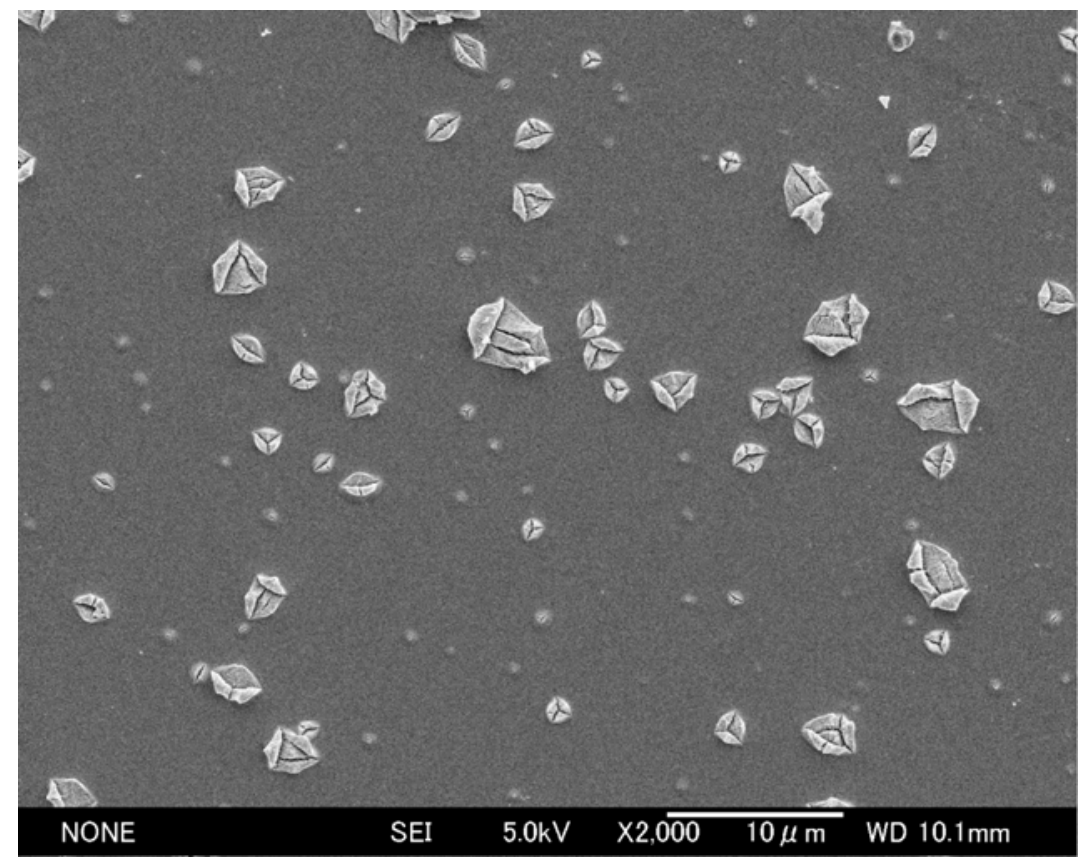

Fig. 8 Scanning electron micrograph of the surface of the niobium specimen thermally treated at $523 \mathrm{~K}$ in air for $1.8 \mathrm{ks}$ and subsequently anodized to $140 \mathrm{~V}$ at $5 \mathrm{~A} \mathrm{~m}^{-2}$ in $0.1 \mathrm{~mol}$ $\mathrm{dm}^{-3}$ ammonium pentaborate electrolyte at $333 \mathrm{~K}$. 

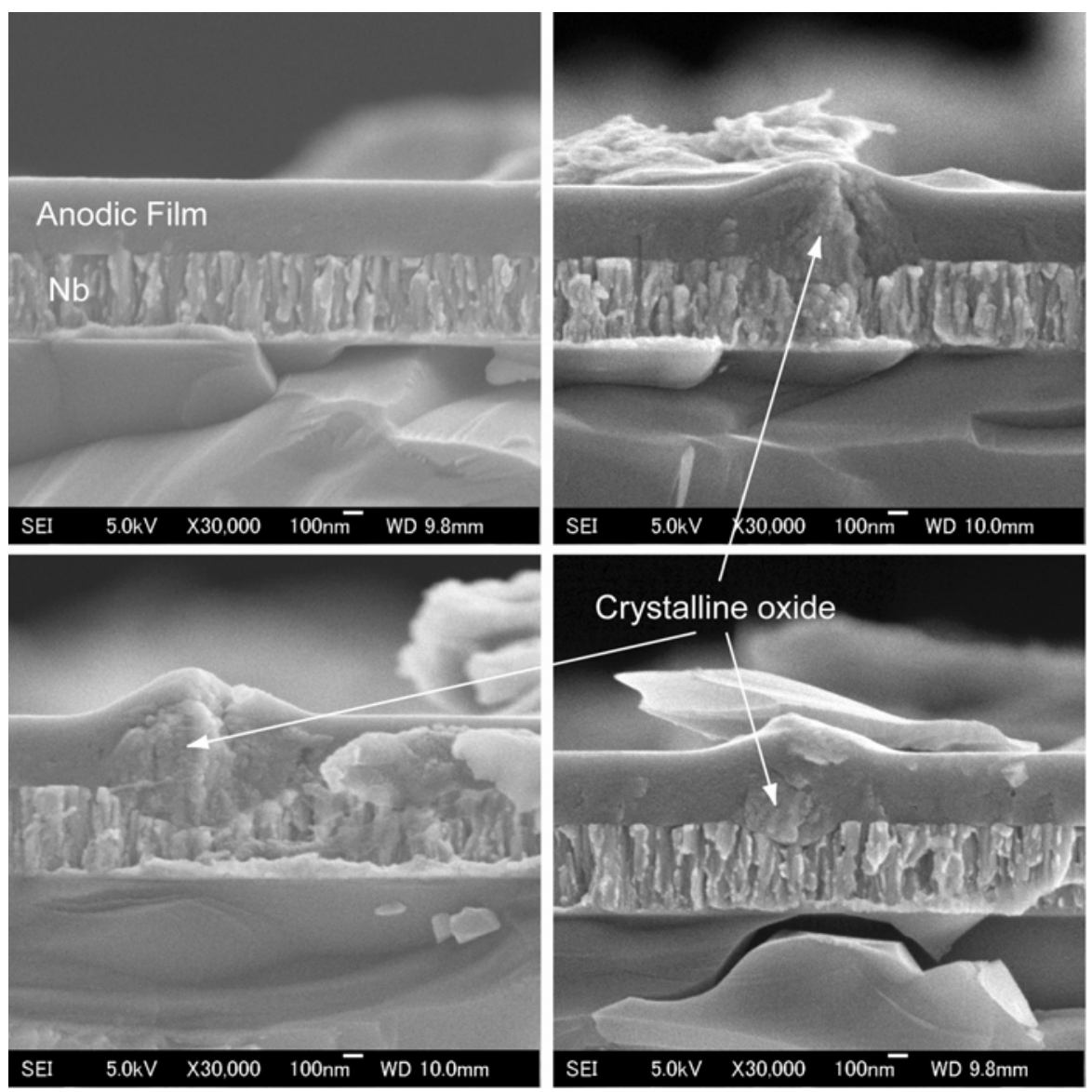

Fig. 9 Scanning electron micrographs of several parts of a cross-section of the niobium specimen thermally treated at $523 \mathrm{~K}$ in air for $1.8 \mathrm{ks}$ and subsequently anodized to $140 \mathrm{~V}$ at 5 $\mathrm{A} \mathrm{m}^{-2}$ in $0.1 \mathrm{~mol} \mathrm{dm}^{-3}$ ammonium pentaborate electrolyte at $333 \mathrm{~K}$. 


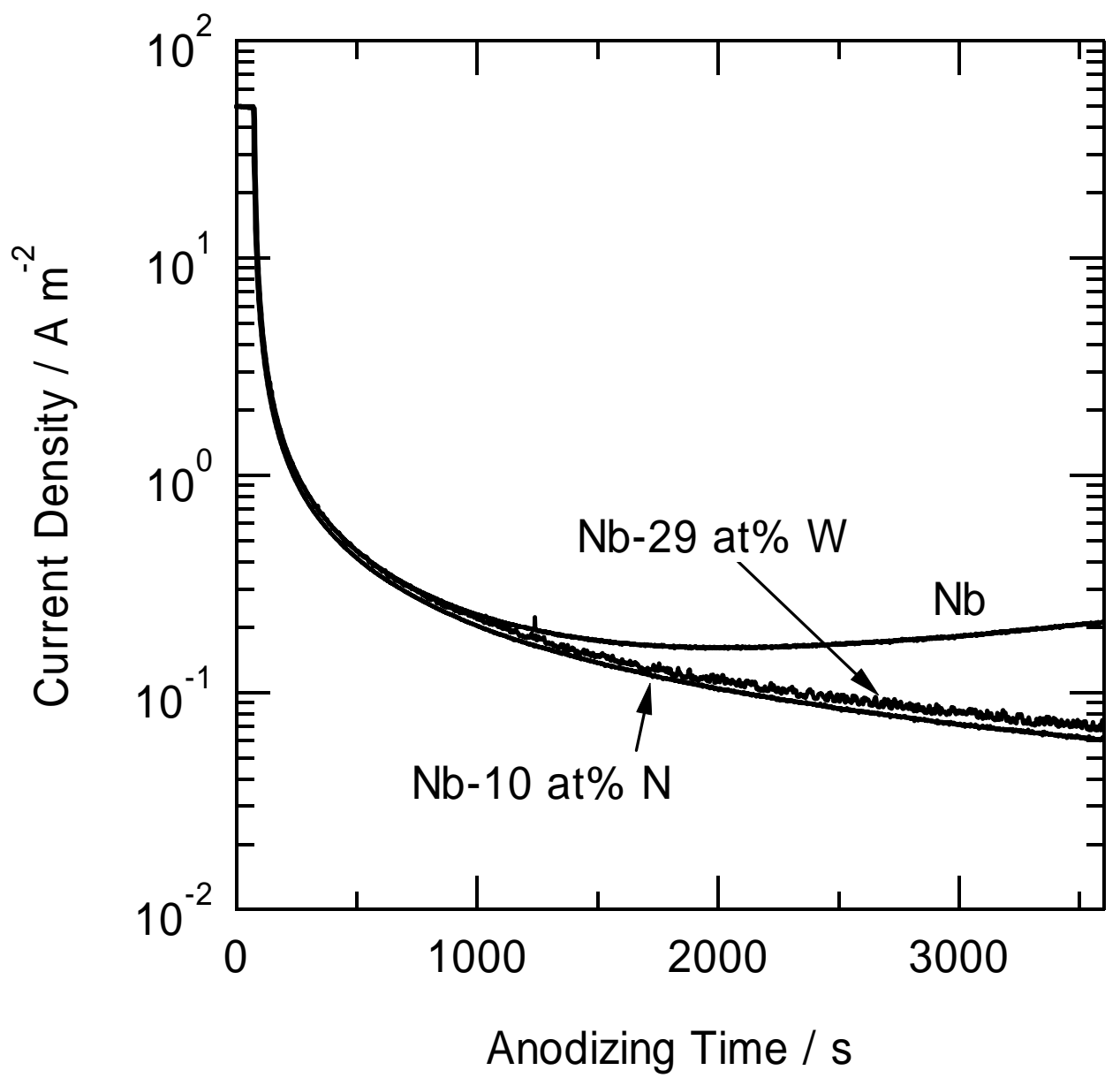

Fig. 10 Current decay curves of the sputter-deposited niobium, Nb-10 at\% N and Nb-29 at\% $\mathrm{W}$ during anodizing at $100 \mathrm{~V}$ in $0.1 \mathrm{~mol} \mathrm{dm}^{-3}$ ammonium pentaborate electrolyte at $333 \mathrm{~K}$. 

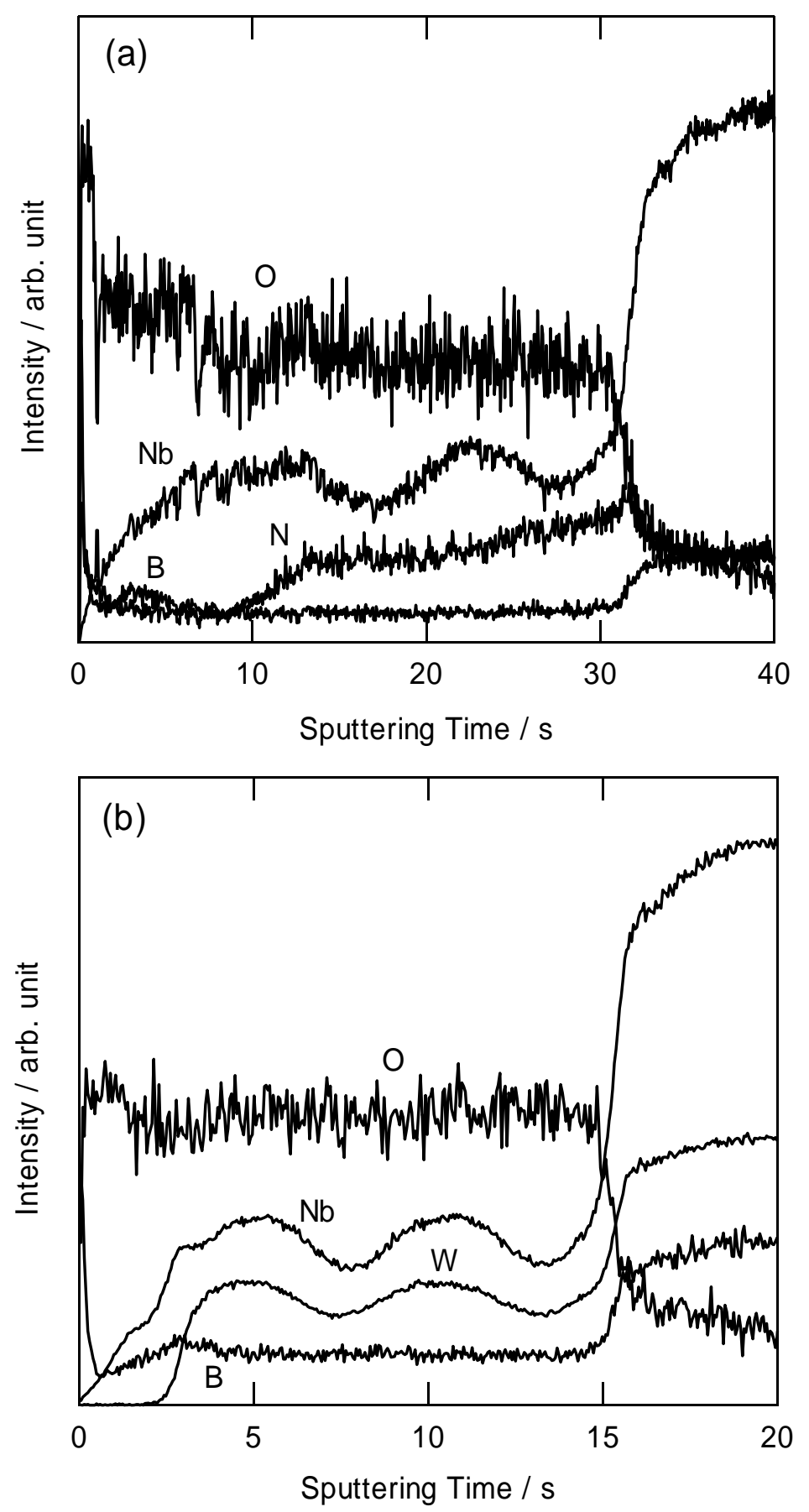

Fig. 11 GDOES depth profiles of the anodic films formed on the sputter-deposited (a) $\mathrm{Nb}-10$ at\% $\mathrm{N}$ and (b) Nb-29 at\% W alloys to $100 \mathrm{~V}$ without current decay at $50 \mathrm{~A} \mathrm{~m}^{-2}$ in 0.1 mol dm${ }^{-3}$ ammonium pentaborate electrolyte at $333 \mathrm{~K}$. 
(a) Nucleation of crystalline oxide

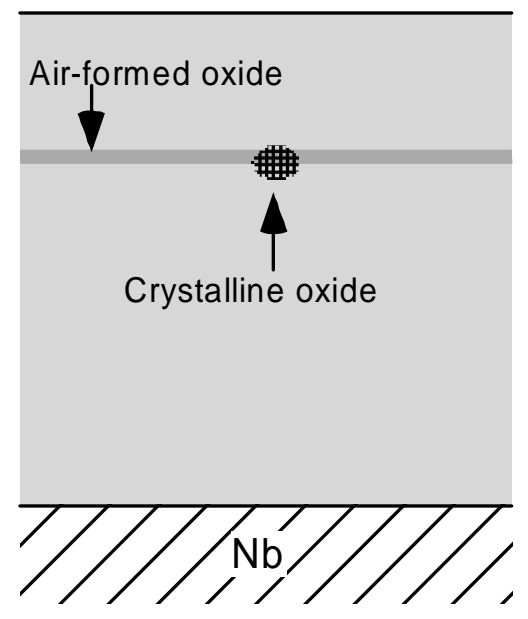

(b) Initial growth of crystalline oxide

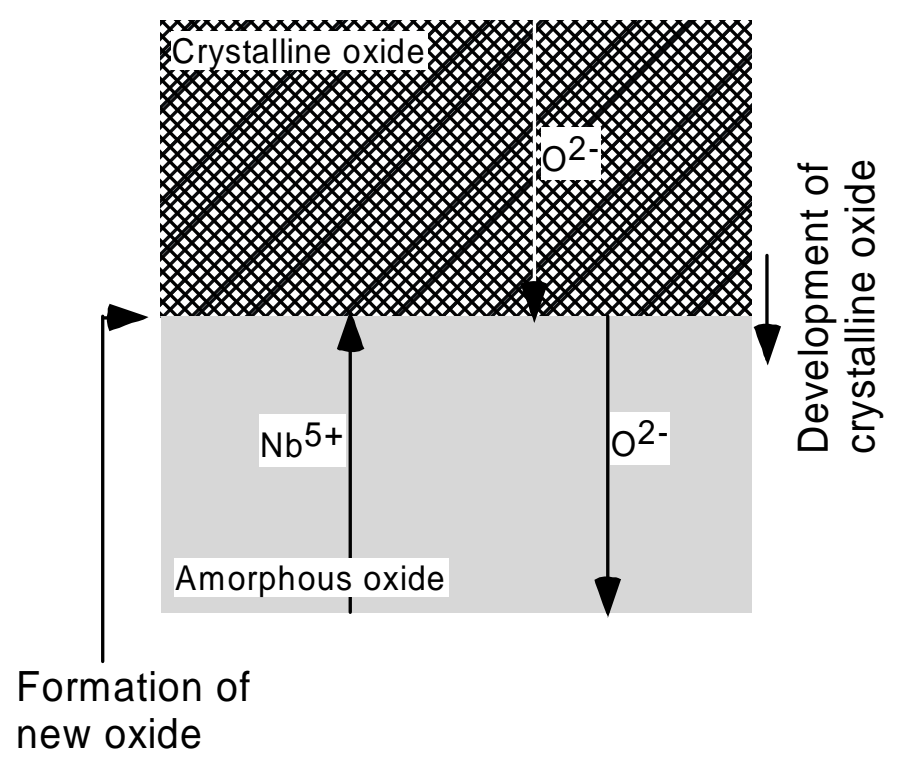

Fig. 12 Schematic illustrations showing (a) nucleation and (b) growth of crystalline anodic niobia during anodizing of niobium. 